\title{
Estimating Glomerular Filtration Rate from Serum Creatinine and Cystatin C
}

\author{
Lesley A. Inker, M.D., Christopher H. Schmid, Ph.D., Hocine Tighiouart, M.S., John H. \\ Eckfeldt, M.D., Ph.D., Harold I. Feldman, M.D., Tom Greene, Ph.D., John W. Kusek, Ph.D., \\ Jane Manzi, Ph.D., Frederick Van Lente, Ph.D., Yaping Lucy Zhang, M.S., Josef Coresh, \\ M.D., Ph.D., and Andrew S. Levey, M.D. for the CKD-EPI Investigators ${ }^{*}$ \\ Tufts Medical Center, Boston (L.A.I., C.H.S., H.T., Y.L.Z., A.S.L.); the University of Minnesota, \\ Minneapolis (J.H.E.); the University of Pennsylvania School of Medicine, Philadelphia (H.I.F.); the \\ University of Utah, Salt Lake City (T.G.); National Institutes of Health, Bethesda, MD (J.W.K.); \\ Johns Hopkins University, Baltimore (J.M., J.C.); and Cleveland Clinic Foundation, Cleveland \\ (F.V.L.)
}

\begin{abstract}
BACKGROUND-Estimates of glomerular filtration rate (GFR) that are based on serum creatinine are routinely used; however, they are imprecise, potentially leading to the overdiagnosis of chronic kidney disease. Cystatin $\mathrm{C}$ is an alternative filtration marker for estimating GFR.

METHODS-Using cross-sectional analyses, we developed estimating equations based on cystatin $\mathrm{C}$ alone and in combination with creatinine in diverse populations totaling 5352 participants from 13 studies. These equations were then validated in 1119 participants from 5 different studies in which GFR had been measured. Cystatin and creatinine assays were traceable to primary reference materials.
\end{abstract}

\begin{abstract}
RESULTS-Mean measured GFRs were 68 and $70 \mathrm{ml}$ per minute per $1.73 \mathrm{~m}^{2}$ of body-surface area in the development and validation data sets, respectively. In the validation data set, the creatinine-cystatin $\mathrm{C}$ equation performed better than equations that used creatinine or cystatin $\mathrm{C}$ alone. Bias was similar among the three equations, with a median difference between measured and estimated GFR of $3.9 \mathrm{ml}$ per minute per $1.73 \mathrm{~m}^{2}$ with the combined equation, as compared with 3.7 and $3.4 \mathrm{ml}$ per minute per $1.73 \mathrm{~m}^{2}$ with the creatinine equation and the cystatin $\mathrm{C}$ equation $(\mathrm{P}=0.07$ and $\mathrm{P}=0.05)$, respectively. Precision was improved with the combined equation (inter-quartile range of the difference, 13.4 vs. 15.4 and $16.4 \mathrm{ml}$ per minute per $1.73 \mathrm{~m}^{2}$, respectively $[\mathrm{P}=0.001$ and $\mathrm{P}<0.001]$ ), and the results were more accurate (percentage of estimates that were $>30 \%$ of measured GFR, 8.5 vs. 12.8 and 14.1, respectively [P<0.001 for both comparisons]). In participants whose estimated GFR based on creatinine was 45 to $74 \mathrm{ml}$ per minute per $1.73 \mathrm{~m}^{2}$, the combined equation improved the classification of measured GFR as either
\end{abstract}

Copyright $\odot 2012$ Massachusetts Medical Society.

Address reprint requests to Dr. Inker at the Division of Nephrology, Tufts Medical Center, 800 Washington St., Box 391, Boston, MA 02111, or at linker@tuftsmedicalcenter.org.

*Additional investigators in the Chronic Kidney Disease Epidemiology Collaboration (CKD-EPI) are listed in the Supplementary Appendix, available at NEJM.org.

Disclosure forms provided by the authors are available with the full text of this article at NEJM.org. 
less than $60 \mathrm{ml}$ per minute per $1.73 \mathrm{~m}^{2}$ or greater than or equal to $60 \mathrm{ml}$ per minute per $1.73 \mathrm{~m}^{2}$ (net reclassification index, 19.4\% [P<0.001]) and correctly reclassified $16.9 \%$ of those with an estimated GFR of 45 to $59 \mathrm{ml}$ per minute per $1.73 \mathrm{~m}^{2}$ as having a GFR of $60 \mathrm{ml}$ or higher per minute per $1.73 \mathrm{~m}^{2}$.

CONCLUSIONS-The combined creatinine-cystatin C equation performed better than equations based on either of these markers alone and may be useful as a confirmatory test for chronic kidney disease. (Funded by the National Institute of Diabetes and Digestive and Kidney Diseases.)

Clinical assessment of kidney function is part of routine medical care for adults. ${ }^{1}$ More than $80 \%$ of clinical laboratories now report an estimated glomerular filtration rate (GFR) when serum creatinine is measured. ${ }^{2}$ Despite standardization of serum creatinine assays, GFR estimates remain relatively imprecise ${ }^{3}$ owing to variation in non-GFR determinants of serum creatinine, which may be affected in both acute and chronic illness. ${ }^{1}$ Such imprecision can potentially result in the misclassification of patients whose estimated GFR is less than $60 \mathrm{ml}$ per minute per $1.73 \mathrm{~m}^{2}$ of body-surface area as having chronic kidney disease, leading to unnecessary diagnostic and therapeutic interventions.

Cystatin $\mathrm{C}$ is considered to be a potential alternative to serum creatinine for estimating GFR. ${ }^{4,5}$ In studies of prognosis, it has been consistently shown to be a better marker than creatinine, ${ }^{6}$ and estimated GFR based on cystatin $\mathrm{C}$ could be used as a confirmatory test for an adverse prognosis in patients with chronic kidney disease. ${ }^{7}$ The validity and accessibility of cystatin $\mathrm{C}$ testing have been greatly improved by the release of a certified reference material for calibrating laboratory assays ${ }^{8,9}$ and by the development of new, less expensive methods for automated analyzers.

Here we report the development and validation of two new equations for estimating GFR one using standardized cystatin $\mathrm{C}$ alone and the other using cystatin $\mathrm{C}$ combined with standardized creatinine - in diverse populations. We evaluated their performance, as compared with existing equations, ${ }^{3,10,11}$ and tested their usefulness in improving the classification of patients with chronic kidney disease.

\section{METHODS}

\section{STUDY DESIGN AND DATA SOURCES}

The Chronic Kidney Disease Epidemiology Collaboration (CKD-EPI) conducted the study under a cooperative agreement with the National Institute of Diabetes and Digestive and Kidney Diseases (NIDDK). CKD-EPI collaborators provided data from clinical research studies and clinical populations. ${ }^{3}$ GFR measurements were based on urinary or plasma clearance of exogenous filtration markers. Data from studies of urinary clearance of iothalamate were used for development and internal validation, and data from studies of other filtration markers were used for external validation. We included 13 studies with 5352 participants, who were randomly divided into separate data sets for development (3522) and internal validation (1830) (see Table S1a in the Supplementary Appendix, available with the full text of this article at NEJM .org). We included 5 other studies with 1119 participants for external validation (Table S1b in the Supplementary Appendix). We excluded studies involving transplant recipients because our preliminary analyses showed large variations 
among these studies in the relationship between serum cystatin C levels and measured GFR. The institutional review boards of all participating institutions approved the study.

The NIDDK was substantially involved in the design of the study and in the collection, analysis, and interpretation of the data; the NIDDK was not required to approve the final manuscript before submission for publication. The first author had full access to all the data in the study, vouches for the integrity of the data and the accuracy of the data analysis for the CKD-EPI database, and wrote the first draft of the manuscript. For a list of collaborators who provided data, see the Supplementary Appendix.

\section{LABORATORY METHODS}

We calibrated serum creatinine assays or measured serum creatinine with the use of the Roche enzymatic method (Roche-Hitachi P-Module instrument with Roche Creatininase Plus assay, Hoffmann-La Roche), traceable to National Institute of Standards and Technology creatinine standard reference material (SRM 967). ${ }^{12}$ We calibrated serum cystatin C assays or measured serum cystatin C on the Siemens Dade Behring Nephelometer (Table S2 in the Supplementary Appendix), traceable to the International Federation of Clinical Chemistry Working Group for Standardization of Serum Cystatin C and the Institute for Reference Materials and Measurements certified reference materials. ${ }^{8,9}$

\section{DEVELOPMENT AND VALIDATION OF EQUATIONS}

Our goal was to develop two equations for estimating GFR: one using serum cystatin C (hereafter referred to as the cystatin $\mathrm{C}$ equation) and another using both serum cystatin $\mathrm{C}$ and serum creatinine (hereafter referred to as the creatinine-cystatin $\mathrm{C}$ equation). As in our previous work, we prespecified a process for developing and validating equations (described in the Methods section in the Supplementary Appendix). In brief, we used least-squares linear regression to relate logarithm-transformed measured GFR to log serum creatinine, log serum cystatin $\mathrm{C}$, age, and sex. We also used nonparametric smoothing splines to characterize the shape of the relationship of log measured GFR with log creatinine and log cystatin $\mathrm{C}$ and then approximated the smoothing splines by means of piecewise linear splines to represent observed nonlinearity. Other candidate variables included the other filtration marker, black race, diabetes status, and weight. The significance threshold for inclusion was $\mathrm{P}<0.01$ for these additional variables and $\mathrm{P}<0.001$ for pairwise interactions among variables. Models that showed improved performance with the use of prespecified criteria were evaluated in the internal validation data set for verification of the statistical significance of predictor variables and interactions. Development and internal-validation data sets were combined into one data set (hereafter referred to as the development data set) to derive final coefficients.

In the external-validation data set, we compared the new equations with each other, with our previous creatinine equation, ${ }^{3}$ and with our prior equations involving cystatin $\mathrm{C}$ that were developed in populations of patients with chronic kidney disease and reexpressed for standardized cystatin C values ${ }^{10,11}$ (Table S3 in the Supplementary Appendix), as well as with the average of the CKD-EPI creatinine equation and the new cystatin $\mathrm{C}$ equation. We compared the performance of equations in the overall data set and in the subgroups, and 
final models were selected according to the ranking of the root-mean-square error overall and within subgroups, clinically significant differences, and ease of application in clinical practice.

\section{METRICS FOR EQUATION PERFORMANCE}

Bias was assessed as the median of the difference between measured GFR and estimated GFR, and precision was assessed as the interquartile range for the difference. ${ }^{3,13}$ Accuracy was assessed as the root-mean-square error and as the percentage of estimates that differed by more than $30 \%$ from the measured GFR $\left(1-\mathrm{P}_{30}\right)$ or by more than $20 \%\left(1-\mathrm{P}_{20}\right)$. Confidence intervals were calculated by means of bootstrap methods (2000 bootstraps). ${ }^{14}$ The significance of the differences among equations was determined with the use of the signed-rank test for bias, the bootstrap method for the interquartile range and root-meansquare error from the 2000 bootstrap samples, and McNemar's test for $1-\mathrm{P}_{30}$ and $1-\mathrm{P}_{20}$.

We evaluated the use of the new equations for the classification of chronic kidney disease in the external-validation population by means of the net reclassification index statistic. ${ }^{15} \mathrm{We}$ compared the proportion of participants who were reclassified as having a measured GFR that was less than $60 \mathrm{ml}$ per minute per $1.73 \mathrm{~m}^{2}$ or greater than or equal to $60 \mathrm{ml}$ per minute per $1.73 \mathrm{~m}^{2}$ on the basis of the new equations versus the CKD-EPI creatinine equation for the overall population and for subgroups according to age, sex, diabetes status, body-mass index, and a creatinine-based estimated GFR of 30 to 89,45 to 74,60 to 74 , and 45 to $59 \mathrm{ml}$ per minute per $1.73 \mathrm{~m}^{2}$. We performed similar analyses for reclassification based on a measured GFR of $90,75,45,30$, and $15 \mathrm{ml}$ per minute per $1.73 \mathrm{~m}^{2}$. Analyses were performed with the use of R, version 2.9.2 (R Development Core Team), and SAS, version 9.2 (SAS Institute), software.

\section{RESULTS}

\section{CHARACTERISTICS OF PARTICIPANTS}

Clinical characteristics of the participants in each data set are shown in Table 1. In the development data set, the mean $( \pm \mathrm{SD})$ measured GFR was $68 \pm 39 \mathrm{ml}$ per minute per $1.73 \mathrm{~m}^{2}$ and ranged between 5 and $198 \mathrm{ml}$ per minute per $1.73 \mathrm{~m}^{2}$. The mean measured GFR was similar in the external-validation data set $\left(70 \pm 41 \mathrm{ml}\right.$ per minute per $\left.1.73 \mathrm{~m}^{2}\right)$, but the mean body weight and mean body-mass index were lower, larger proportions of the patients were older and had diabetes, and a smaller proportion of the patients were black.

\section{FORMULATION OF EQUATIONS AND THEIR PERFORMANCE IN THE DEVELOPMENT DATA SET}

Table 2 shows the formulas for the two new equations in the development data set - the cystatin $\mathrm{C}$ equation and the creatinine-cystatin $\mathrm{C}$ equation - as well as our earlier creatinine equation. ${ }^{3}$ (For further details, see Table S4 in the Supplementary Appendix.) The addition of race as a variable did not improve the performance of the cystatin $C$ equation overall or in subgroups defined by race, but it did improve the performance of the creatinine-cystatin C equation (Table S6 in the Supplementary Appendix). A more detailed 
explanation of the performance of these and other new equations is included in Tables S5 through S9 in the Supplementary Appendix.

\section{PERFORMANCE OF NEW EQUATIONS IN THE VALIDATION DATA SET}

In the external-validation data set, the new equations based on cystatin $C$ had less bias than the equations based on cystatin $C$ that had previously been developed in populations of patients with chronic kidney disease, especially at an estimated GFR of 60 to $89 \mathrm{ml}$ per minute per $1.73 \mathrm{~m}^{2}$ (Table S10 in the Supplementary Appendix). Overall, the new creatinine-cystatin $\mathrm{C}$ equation performed better than the equations that used either creatinine alone or cystatin $\mathrm{C}$ alone. Although bias was similar for all three equations (median difference, $3.9 \mathrm{ml}$ per minute per $1.73 \mathrm{~m}^{2}$ for the combined equation vs. 3.7 and $3.4 \mathrm{ml}$ per minute per $1.73 \mathrm{~m}^{2}$ for the creatinine-alone and cystatin $\mathrm{C}$-alone equations $[\mathrm{P}=0.07$ and $\mathrm{P}$ $=0.05]$, respectively), precision was improved with use of the creatinine-cystatin C equation (interquartile range for the difference, $13.4 \mathrm{ml}$ per minute per $1.73 \mathrm{~m}^{2}$ ), as compared with the creatinine equation and with the cystatin $\mathrm{C}$ equation (interquartile range for the difference, 15.4 and $16.4 \mathrm{ml}$ per minute per $1.73 \mathrm{~m}^{2}[\mathrm{P}=0.001$ and $\left.\mathrm{P}<0.001]\right)$, as was accuracy $\left(1-\mathrm{P}_{30}, 8.5 \%\right.$, vs. $12.8 \%$ for the creatinine equation and $14.1 \%$ for the cystatin $\mathrm{C}$ equation [ $\mathrm{P}<0.001$ for both comparisons]; relative reductions, $34 \%$ and $40 \%$, respectively; $1-\mathrm{P}_{20}, 22.8 \%$ vs. $32.9 \%$ and $33.0 \%$, respectively [ $\mathrm{P}<0.001$ for both comparisons]; relative reduction, 31\% for both) (Table 3, and Fig. S1 in the Supplementary Appendix). Across the range of estimated GFRs from 15 to $120 \mathrm{ml}$ per minute per $1.73 \mathrm{~m}^{2}$, the cystatin C equation and the creatinine equation were similar in terms of both bias and accuracy (Fig. 1). The mean of the estimated GFRs derived from the creatinine and cystatin C equations did not differ significantly from that of the creatinine-cystatin $\mathrm{C}$ equation. Results were generally consistent across studies and across subgroups defined by age, sex, and diabetes status (Table S11 and Fig. S2 in the Supplementary Appendix).

Using an estimated GFR threshold of less than $60 \mathrm{ml}$ per minute per $1.73 \mathrm{~m}^{2}$, we found that the combined equation, as compared with the creatinine equation, reclassified $5.5 \%$ of participants. Reclassification was more often correct than incorrect with a measured GFR threshold of less than $60 \mathrm{ml}$ per minute per $1.73 \mathrm{~m}^{2}$ (net reclassification index, 4.9; 95\% confidence interval $[\mathrm{CI}], 2.2$ to $7.7 ; \mathrm{P}<0.001$ ) (Table 4). For participants with a creatininebased estimated GFR of 45 to $74 \mathrm{ml}$ per minute per $1.73 \mathrm{~m}^{2}$, the combined equation improved classification (net reclassification index, 19.4; 95\% CI, 8.7 to $30.1 ; \mathrm{P}<0.001$ ), with correct reclassification of 28 of 166 patients (16.9\%) with a creatinine-based estimated GFR of 45 to $59 \mathrm{ml}$ per minute per $1.73 \mathrm{~m}^{2}$ to $60 \mathrm{ml}$ per minute per $1.73 \mathrm{~m}^{2}$ or higher. In this subgroup, results were similar when the cystatin $C$ equation was used. Results were consistent across most of the subgroups defined by age, sex, diabetes status, body-mass index, and other measured GFR thresholds (Tables S12 and S13 in the Supplementary Appendix).

\section{DISCUSSION}

Accurate assessment of GFR is essential for interpreting the symptoms, signs, and laboratory abnormalities that may indicate kidney disease; for drug dosing; and for detecting 
and managing chronic kidney disease and assessing the prognosis. A reduction in GFR to less than $60 \mathrm{ml}$ per minute per $1.73 \mathrm{~m}^{2}$ for 3 months or longer is a diagnostic criterion for chronic kidney disease and is associated with an increased risk of adverse outcomes, including death. ${ }^{16-19}$ Bias with the new, combined creatinine-cystatin $C$ equation and with the average of the new cystatin $\mathrm{C}$ equation and the creatinine equation was similar to that with the individual creatinine and cystatin $\mathrm{C}$ equations, but they had greater precision and accuracy and resulted in more accurate classification of measured GFR as less than $60 \mathrm{ml}$ per minute per $1.73 \mathrm{~m}^{2}$ - the threshold for the diagnosis of chronic kidney disease.

Since cystatin $\mathrm{C}$ is less affected by muscle mass and diet than is creatinine, ${ }^{4,5,20}$ it has been widely anticipated that cystatin $\mathrm{C}$ would provide a more accurate estimate of GFR than would creatinine. Nevertheless, GFR estimates based on equations that use cystatin $\mathrm{C}$ as the sole filtration marker are not more accurate than creatinine-based estimates, suggesting that unmeasured and largely unknown non-GFR determinants of cystatin $\mathrm{C}$ are similar in magnitude to those of creatinine. The advantage of the cystatin $\mathrm{C}$-based equation over the creatinine-based equation is that it is less subject to the effects of age, sex, and race. Indeed, we found that in the development and internal-validation data sets, the addition of race as a variable did not improve the performance of the cystatin $\mathrm{C}$-based equation in the black subgroup. Given the difficulties in assigning race and the lack of information about race in laboratory and administrative databases, a GFR estimating equation that does not require race may be more generalizable across populations and could greatly facilitate the use of estimated GFR in clinical practice, research, and public health programs.

The equation that combines creatinine and cystatin $\mathrm{C}$ provides the most precise and accurate estimate of GFR across the range of GFRs and in subgroups based on demographic and clinical characteristics. This improvement holds true even among participants with a bodymass index (the weight in kilograms divided by the square of the height in meters) of less than 20 - a subgroup in which creatinine-based GFR estimates are known to be less accurate. To explain this improved precision, we hypothesize that errors due to the non-GFR determinants of creatinine and cystatin $\mathrm{C}$ are independent and smaller in an equation that uses both markers than in an equation that uses only one marker. Possible reasons for the continued imprecision are the residual contribution of non-GFR determinants of each marker, as well as physiologic variation in GFR and error in measurement of GFR. ${ }^{21}$ The former limitation can be addressed by including additional markers; the latter reflects imprecision in our reference standards rather than errors in estimating equations.

It may be useful to consider more widespread use of GFR estimates based on cystatin C, either alone or in combination with creatinine. Our data suggest that cystatin $\mathrm{C}$ should not replace creatinine in general practice; however, the combination of creatinine and cystatin $\mathrm{C}$ provides more precise GFR estimates, which may be useful for specific purposes. For example, the addition of cystatin $\mathrm{C}$ could be used as a confirmatory test for the diagnosis of chronic kidney disease in patients with a decreased GFR as estimated from creatinine. Peralta and colleagues found that cystatin $\mathrm{C}$ can be used to confirm a high risk of a poor prognosis for persons whose estimated GFR is decreased according to the creatinine equation. ${ }^{7,22}$ Data from the National Health and Nutrition Examination Surveys ${ }^{23}$ suggest that $3.6 \%$ of U.S. adults would be classified as having chronic kidney disease solely on the 
basis of a creatinine-based GFR estimate of 45 to $59 \mathrm{ml}$ per minute per $1.73 \mathrm{~m}^{2}$. Our data suggest that a strategy of measuring cystatin $\mathrm{C}$ when the creatinine-based estimate is in this range and then reestimating GFR with the use of both these markers could correctly reclassify a substantial proportion of such patients as not having chronic kidney disease and not being at high risk. This more accurate classification would result in more selective use of resources, such as tests for complications of chronic kidney disease, adjustment of medication doses, and referrals to nephrologists. ${ }^{7,22}$

Cystatin $\mathrm{C}$ could also be used to screen for chronic kidney disease among persons who have a creatinine-based GFR estimate of 60 to $74 \mathrm{ml}$ per minute per $1.73 \mathrm{~m}^{2}$ without albuminuria (10.9\% of U.S. adults) or to obtain a more accurate estimation of GFR in patients with muscle wasting or chronic illness. ${ }^{24}$ The addition of cystatin $\mathrm{C}$ testing could increase laboratory costs; therefore, clinical and laboratory practice guidelines need to be developed that specify indications and preferred diagnostic strategies for such testing and laboratory reporting, taking into consideration local public health priorities, clinical practice patterns, and costs and benefits.

The strengths of this study include the use of large databases for the development and validation of the new equation and a prespecified, rigorous analytic plan for testing all variables in the development data set. The pooled development and validation databases included participants with diverse clinical characteristics, resulting in greater general applicability than was provided by our previously developed cystatin C equations. By comparing the various equations in a separate validation data set, we were able to overcome limitations due to interstudy differences in participant characteristics and in methods for measuring GFR and serum creatinine and cystatin C. Finally, the equations are expressed for standardized creatinine and cystatin $C$ values.

Our study has limitations. First, our findings may reflect the specific characteristics of the studies included in our database. It is possible that within more homogeneous subgroups greater precision would be observed. Second, participants with a higher GFR may not be representative of the general population, and none of the data sets came from populations of patients with markedly reduced muscle mass or malnutrition, in whom cystatin $\mathrm{C}$ testing might be expected to offer a substantial improvement over creatinine testing. Third, there were essentially no racial or ethnic minorities other than blacks in the development data set and there were very few blacks in the validation data set. We suggest that other investigators test our new equations in other racial and ethnic groups. Fourth, we had incomplete data on measures of muscle mass and other clinical conditions and medications that might affect serum creatinine or cystatin C levels independently of GFR. Fifth, errors in the measured GFR may account for some of the observed imprecision, thus limiting interpretation of the analyses when participants were categorized according to measured GFR. Finally, our equations may not perform well in transplant recipients; such patients were not included in this analysis, since we noted differences between transplant recipients and other patients with chronic kidney disease, as have others. ${ }^{25}$

In conclusion, the combination of serum creatinine and serum cystatin $\mathrm{C}$ is more accurate than either marker alone for estimating GFR. The new equations represent an advance over 
currently available equations across the range of GFR and in relevant subgroups. Reporting estimated GFR as determined by means of these equations when serum cystatin $\mathrm{C}$ is measured should greatly facilitate the clinical interpretation of cystatin $\mathrm{C}$ measurements. Our data suggest that estimated GFR based on serum cystatin C could be used as a confirmatory test for chronic kidney disease.

\section{Supplementary Material}

Refer to Web version on PubMed Central for supplementary material.

\section{Acknowledgments}

Supported by grants (UO1 DK 053869, UO1 DK 067651, and UO1 DK 35073) from the National Institute of Diabetes and Digestive and Kidney Diseases.

We thank Dr. Aghogho Okparavero for providing assistance with communications and manuscript preparation. (Additional acknowledgments are provided in the Supplementary Appendix.)

\section{References}

1. Stevens LA, Coresh J, Greene T, Levey AS. Assessing kidney function - measured and estimated glomerular filtration rate. N Engl J Med. 2006; 354:2473-83. [PubMed: 16760447]

2. College of American Pathologists. Current status of reporting estimated glomerular filtration rate (eGFR). 2011. (http://www.cap.org/apps/cap.portal?_nfpb=true\&cntvwrPtlt_actionOverride= \%2Fportlets\%2FcontentViewer\%2Fshow\&_windowLabel=cntvwrPtlt\&cntvwrPtlt $\% 7$ BactionForm.contentReference $\% 7 \mathrm{D}=$ committees $\% 2$ Fchemistry \%2Fchemistry_resources.html\&_state=maximized\&pageLabel=cntvwr)

3. Levey AS, Stevens LA, Schmid CH, et al. A new equation to estimate glomerular filtration rate. Ann Intern Med. 2009; 150:604-12. [Erratum, Ann Intern Med 2011; 155:408.]. [PubMed: 19414839]

4. Tangri N, Stevens LA, Schmid CH, et al. Changes in dietary protein intake has no effect on serum cystatin $\mathrm{C}$ levels independent of the glomerular filtration rate. Kidney Int. 2011; 79:471-4. [PubMed: 20980977]

5. Stevens LA, Schmid CH, Greene T, et al. Factors other than glomerular filtration rate affect serum cystatin C levels. Kidney Int. 2009; 75:652-60. [PubMed: 19119287]

6. Shlipak MG, Sarnak MJ, Katz R, et al. Cystatin C and the risk of death and cardiovascular events among elderly persons. N Engl J Med. 2005; 352:2049-60. [PubMed: 15901858]

7. Peralta CA, Shlipak MG, Judd S, et al. Detection of chronic kidney disease with creatinine, cystatin $\mathrm{C}$, and urine albumin-to-creatinine ratio and association with progression to end-stage renal disease and mortality. JAMA. 2011; 305:1545-52. [PubMed: 21482744]

8. Grubb A, Blirup-Jensen S, Lindstrom V, Schmidt C, Althaus H, Zegers I. First certified reference material for cystatin C in human serum ERM-DA471/IFCC. Clin Chem Lab Med. 2010; 48:161921. [PubMed: 21034257]

9. Blirup-Jensen S, Grubb A, Lindstrom V, Schmidt C, Althaus H. Standardization of cystatin C: development of primary and secondary reference preparations. Scand J Clin Lab Invest Suppl. 2008; 241:67-70. [PubMed: 18569968]

10. Inker LA, Eckfeldt J, Levey AS, et al. Expressing the CKD-EPI (Chronic Kidney Disease Epidemiology Collaboration) cystatin $\mathrm{C}$ equations for estimating GFR with standardized serum cystatin C values. Am J Kidney Dis. 2011; 58:682-4. [PubMed: 21855190]

11. Stevens LA, Coresh J, Schmid CH, et al. Estimating GFR using serum cystatin $\mathrm{C}$ alone and in combination with serum creatinine: a pooled analysis of 3,418 individuals with CKD. Am J Kidney Dis. 2008; 51:395-406. [PubMed: 18295055] 
12. Levey AS, Coresh J, Greene T, et al. Expressing the Modification of Diet in Renal Disease Study equation for estimating glomerular filtration rate with standardized serum creatinine values. Clin Chem. 2007; 53:766-72. [PubMed: 17332152]

13. Stevens LA, Zhang Y, Schmid CH. Evaluating the performance of equations for estimating glomerular filtration rate. J Nephrol. 2008; 21:797-807. [PubMed: 19034863]

14. Efron, B.; Tibshirani, RJ. An introduction to the bootstrap. New York: Chapman and Hall; 1993.

15. Peucina MJ, D’ Agostino RB Sr, D’Agostino RB Jr, Vasan RS. Evaluating the added predictive ability of a new marker: from area under the ROC curve to reclassification and beyond. Stat Med. 2008; 27:157-172. 207-12. [PubMed: 17569110]

16. Chronic Kidney Disease Prognosis Consortium. Association of estimated glomerular filtration rate and albuminuria with all-cause and cardiovascular mortality in general population cohorts: a collaborative meta-analysis. Lancet. 2010; 375:2073-81. [PubMed: 20483451]

17. van der Velde M, Matsushita K, Coresh J, et al. Lower estimated glomerular filtration rate and higher albuminuria are associated with all-cause and cardiovascular mortality: a collaborative meta-analysis of high-risk population cohorts. Kidney Int. 2011; 79:1341-52. [PubMed: 21307840]

18. Gansevoort RT, Matsushita K, van der Velde M, et al. Lower estimated GFR and higher albuminuria are associated with adverse kidney outcomes in both general and high-risk populations: a collaborative meta-analysis of general and high-risk population cohorts. Kidney Int. 2011; 80:93-104. [PubMed: 21289597]

19. Astor BC, Matsushita K, Gansevoort RT, et al. Lower estimated glomerular filtration rate and higher albuminuria are associated with mortality and end-stage renal disease: a collaborative metaanalysis of kidney disease population cohorts. Kidney Int. 2011; 79:1331-40. [PubMed: 21289598]

20. Vinge E, Lindergård B, Nilsson-Ehle P, Grubb A. Relationships among serum cystatin C, serum creatinine, lean tissue mass and glomerular filtration rate in healthy adults. Scand J Clin Lab Invest. 1999; 59:587-92. [PubMed: 10691049]

21. Kwong YT, Stevens LA, Selvin E, et al. Imprecision of urinary iothalamate clearance as a goldstandard measure of GFR decreases the diagnostic accuracy of kidney function estimating equations. Am J Kidney Dis. 2010; 56:39-49. [PubMed: 20537455]

22. Peralta CA, Katz R, Sarnak MJ, et al. Cystatin C identifies chronic kidney disease patients at higher risk for complications. J Am Soc Nephrol. 2011; 22:147-55. [PubMed: 21164029]

23. Centers for Disease Control and Prevention. National Health and Nutrition Examination Survey. (http://www.cdc.gov/nchs/nhanes.htm)

24. Stevens LA, Padala S, Levey AS. Advances in glomerular filtration rate-estimating equations. Curr Opin Nephrol Hypertens. 2010; 19:298-307. [PubMed: 20393287]

25. Rule AD, Bergstralh EJ, Slezak JM, Bergert J, Larson TS. Glomerular filtration rate estimated by cystatin C among different clinical presentations. Kidney Int. 2006; 69:399-405. [PubMed: 16408133] 


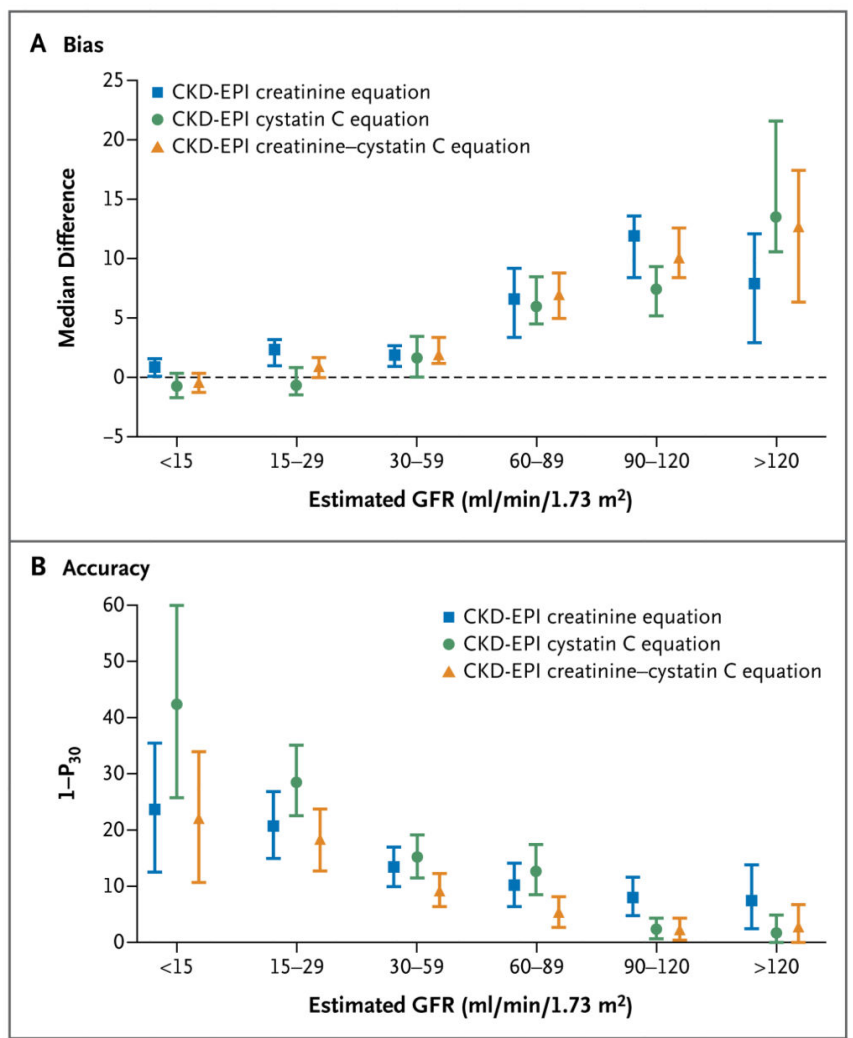

Figure 1. Performance of Three Equations for Estimating Glomerular Filtration Rate (GFR) Panel A shows the median difference between measured and estimated GFR. The bias is similar with the equation using creatinine alone, the equation using cystatin $\mathrm{C}$ alone, and the combined creatinine-cystatin $\mathrm{C}$ equation. Panel B shows the accuracy of the three equations with respect to the percentage of estimates that were greater than $30 \%$ of the measured GFR $\left(1-\mathrm{P}_{30}\right)$. I bars indicate $95 \%$ confidence intervals. 


\section{Table 1}

Characteristics of Study Participants, According to Data Set. ${ }^{*}$

\begin{tabular}{|c|c|c|c|}
\hline Characteristic & $\begin{array}{l}\text { Development and Internal } \\
\text { Validation }(\mathbf{N}=\mathbf{5 3 5 2})\end{array}$ & $\begin{array}{l}\text { External Validation }(\mathrm{N}= \\
\text { 1119) }\end{array}$ & P Value \\
\hline Age - yr & $47 \pm 15$ & $50 \pm 17$ & $<0.001$ \\
\hline \multicolumn{4}{|l|}{ Age group - no. (\%) } \\
\hline$<40 \mathrm{yr}$ & $2008(38)$ & $357(32)$ & $<0.001$ \\
\hline $40-65 \mathrm{yr}$ & $2625(49)$ & $530(47)$ & \\
\hline$>65 \mathrm{yr}$ & $719(13)$ & $232(21)$ & \\
\hline Male sex — no. (\%) & $3107(58)$ & $663(59)$ & 0.46 \\
\hline Black race - no. $(\%)^{\dagger}$ & $2123(40)$ & $30(3)$ & $<0.001$ \\
\hline Diabetes — no. $(\%)$ & $1726(32)$ & $594(53)$ & $<0.001$ \\
\hline \multicolumn{4}{|l|}{ Body-mass index $x^{t}$} \\
\hline Mean & $28 \pm 6$ & $25 \pm 4$ & $<0.001$ \\
\hline$<20-$ no. $(\%)$ & $214(4)$ & $81(7)$ & $<0.001$ \\
\hline $20-24-$ no. $(\%)$ & $1585(30)$ & $503(45)$ & \\
\hline $25-30-$ no. $(\%)$ & $1881(35)$ & $386(35)$ & \\
\hline$>30-$ no. $(\%)$ & $1671(31)$ & $149(13)$ & \\
\hline Mean weight $-\mathrm{kg}$ & $83 \pm 20$ & $74 \pm 15$ & $<0.001$ \\
\hline Mean height $-\mathrm{cm}$ & $171 \pm 10$ & $170 \pm 9$ & 0.017 \\
\hline Mean body-surface area $-\mathrm{m}^{2}$ & $1.94 \pm 0.24$ & $1.85 \pm 0.21$ & $<0.001$ \\
\hline Mean serum cystatin $\mathrm{C}-\mathrm{ml} /$ liter & $1.4 \pm 0.7$ & $1.5 \pm 0.8$ & 0.01 \\
\hline Mean serum creatinine $-\mathrm{mg} / \mathrm{dl}{ }^{\S}$ & $1.6 \pm 0.9$ & $1.6 \pm 1.1$ & 0.15 \\
\hline Mean measured GFR $-\mathrm{ml} / \mathrm{min} / 1.73 \mathrm{~m}^{2}$ of body-surface area & $68 \pm 39$ & $70 \pm 41$ & 0.13 \\
\hline \multicolumn{4}{|l|}{ Measured GFR - no. (\%) } \\
\hline$<15 \mathrm{ml} / \mathrm{min} / 1.73 \mathrm{~m}^{2}$ & $160(3)$ & $51(5)$ & $<0.001$ \\
\hline $15-29 \mathrm{ml} / \mathrm{min} / 1.73 \mathrm{~m}^{2}$ & $785(15)$ & $166(15)$ & \\
\hline $30-59 \mathrm{ml} / \mathrm{min} / 1.73 \mathrm{~m}^{2}$ & $1765(33)$ & $316(28)$ & \\
\hline $60-89 \mathrm{ml} / \mathrm{min} / 1.73 \mathrm{~m}^{2}$ & $1105(21)$ & $215(19)$ & \\
\hline $90-119 \mathrm{ml} / \mathrm{min} / 1.73 \mathrm{~m}^{2}$ & $862(16)$ & $199(18)$ & \\
\hline$>120 \mathrm{ml} / \mathrm{min} / 1.73 \mathrm{~m}^{2}$ & $675(13)$ & $172(15)$ & \\
\hline
\end{tabular}

*Plus-minus values are means \pm SD. GFR denotes glomerular filtration rate.

${ }^{\dagger}$ Race was determined by the investigators or by self-report, depending on the study.

${ }^{*}$ The body-mass index is the weight in kilograms divided by the square of the height in meters.

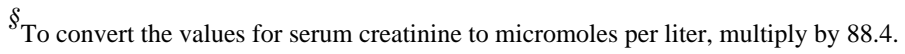


Table 2

Creatinine Equation (CKD-EPI 2009), Cystatin C Equation (CKD-EPI 2012), and Creatinine-Cystatin C Equation (CKD-EPI 2012) for Estimating GFR, Expressed for Specified Sex, Serum Creatinine Level, and Serum Cystatin C Level.*

\begin{tabular}{|c|c|c|c|}
\hline Basis of Equation and Sex & $\begin{array}{l}\text { Serum Creatinine }{ }^{\dagger} \\
m g / d l\end{array}$ & $\begin{array}{c}\text { Serum Cystatin C } \\
m g / l i t e r\end{array}$ & Equation for Estimating GFR \\
\hline \multicolumn{4}{|l|}{ CKD-EPI creatinine equation } \\
\hline Female & $\unlhd 0.7$ & & $144 \times(\mathrm{Scr} / 0.7)^{-0.329} \times 0.993^{\mathrm{Age}}[\times 1.159$ if black $]$ \\
\hline Female & $>0.7$ & & $144 \times(\mathrm{Scr} / 0.7)^{-1.209} \times 0.993^{\mathrm{Age}}[\times 1.159$ if black $]$ \\
\hline Male & $\unlhd) .9$ & & $141 \times(\mathrm{Scr} / 0.9)^{-0.411} \times 0.993^{\mathrm{Age}}[\times 1.159$ if black $]$ \\
\hline Male & $>0.9$ & & $141 \times(\mathrm{Scr} / 0.9)^{-1.209} \times 0.993^{\mathrm{Age}}[\times 1.159$ if black $]$ \\
\hline \multicolumn{4}{|l|}{ CKD-EPI cystatin C equation $\S$} \\
\hline Female or male & & $\unlhd) .8$ & $133 \times(\text { Scys } / 0.8)^{-0.499} \times 0.996^{\text {Age }}[\times 0.932$ if female $]$ \\
\hline Female or male & & $>0.8$ & $133 \times(\text { Scys } / 0.8)^{-1.328} \times 0.996^{\mathrm{Age}}[\times 0.932$ if female $]$ \\
\hline \multicolumn{4}{|l|}{$\begin{array}{l}\text { CKD-EPI creatinine- } \\
\text { cystatin C equation } \mathbb{I}\end{array}$} \\
\hline \multirow[t]{2}{*}{ Female } & $\$ 0.7$ & $\unlhd) .8$ & $\begin{array}{c}130 \times(\mathrm{Scr} / 0.7)^{-0.248} \times\left(\begin{array}{c}\mathrm{Scys} / 0.8)^{-0.375} \\
\text { black }]\end{array}\right. \\
00.995^{\text {Age }}[\times 1.08 \text { if }\end{array}$ \\
\hline & & $>0.8$ & 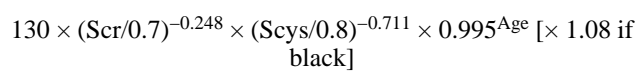 \\
\hline \multirow[t]{2}{*}{ Female } & $>0.7$ & $\unlhd) .8$ & $\begin{array}{c}130 \times(\mathrm{Scr} / 0.7)^{-0.601} \times\left(\begin{array}{c}\mathrm{Scys} / 0.8)^{-0.375} \\
\text { black }]\end{array}\right. \\
00.995^{\text {Age }}[\times 1.08 \text { if }\end{array}$ \\
\hline & & $>0.8$ & $130 \times(\mathrm{Scr} / 0.7)^{-0.601} \times\left(\begin{array}{c}\mathrm{Scys} / 0.8)^{-0.711} \\
\text { black }]\end{array} \times 0.995^{\mathrm{Age}}[\times 1.08\right.$ if \\
\hline \multirow[t]{2}{*}{ Male } & $\unlhd 0.9$ & $\unlhd) .8$ & $\begin{array}{c}135 \times(\mathrm{Scr} / 0.9)^{-0.207} \times\left(\begin{array}{c}\mathrm{Scys} / 0.8)^{-0.375} \\
\text { black }]\end{array}\right. \\
00.995^{\mathrm{Age}}[\times 1.08 \text { if }\end{array}$ \\
\hline & & $>0.8$ & $135 \times(\mathrm{Scr} / 0.9)^{-0.207} \times\left(\begin{array}{c}\mathrm{Scys} / 0.8)^{-0.711} \\
\text { black }]\end{array}\right.$ \\
\hline \multirow[t]{2}{*}{ Male } & $>0.9$ & $\unlhd) .8$ & $135 \times(\mathrm{Scr} / 0.9)^{-0.601} \times\left(\begin{array}{c}\mathrm{Scys} / 0.8)^{-0.375} \\
\text { black }]\end{array}\right.$ \\
\hline & & $>0.8$ & $135 \times(\mathrm{Scr} / 0.9)^{-0.601} \times\left(\begin{array}{c}\mathrm{Scys} / 0.8)^{-0.711} \\
\text { black }]\end{array} \times 0.995^{\mathrm{Age}}[\times 1.08\right.$ if \\
\hline
\end{tabular}

* See Table S3 in the Supplementary Appendix for equations developed in the populations with chronic kidney disease.

${ }^{\dagger}$ To convert the values for serum creatinine to micromoles per liter, multiply by 88.4 .

${ }^{*}$ The CKD-EPI creatinine equation (2009) that we developed previously 3 can be expressed as a single equation: $141 \times \min (\mathrm{Scr} / \kappa, 1)^{a} \times$ $\max (\mathrm{Scr} / \kappa, 1)^{-1.209} \times 0.993^{\mathrm{Age}}[\times 1.018$ if female] [ $\times 1.159$ if black], where Scr is serum creatinine, $\kappa$ is 0.7 for females and 0.9 for males, $a$ is -0.329 for females and -0.411 for males, min is the minimum of $\mathrm{Scr} / \kappa$ or 1 , and max is the maximum of $\mathrm{Scr} / \kappa$ or 1 . 


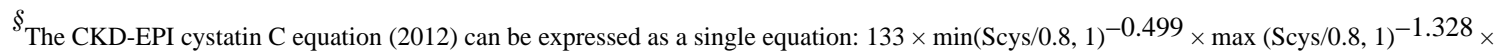
$0.996^{\mathrm{Age}}[\times 0.932$ if female], where Scys is serum cystatin C, min indicates the minimum of Scr/ $\kappa$ or 1 , and max indicates the maximum of Scys $/ \kappa$ or 1.

${ }^{I}$ The CKD-EPI creatinine-cystatin C equation (2012) can be expressed as a single equation: $135 \times \min (\mathrm{Scr} / \kappa, 1)^{a} \times \max (\mathrm{Scr} / \kappa, 1)^{-0.601} \times$ $\min (\mathrm{Scys} / 0.8,1)^{-0.375} \times \max (\mathrm{Scys} / 0.8,1)^{-0.711} \times 0.995^{\mathrm{Age}}[\times 0.969$ if female] [ $\times 1.08$ if black], where Scr is serum creatinine, Scys is serum cystatin C, $\kappa$ is 0.7 for females and 0.9 for males, $\alpha$ is -0.248 for females and -0.207 for males, min indicates the minimum of Scr/ $\kappa$ or 1 , and max indicates the maximum of $\mathrm{Scr} / \kappa$ or 1. 
Table 3

Use of the CKD-EPI Creatinine Equation (2009), CKD-EPI Cystatin C Equation (2012), and CKD-EPI Creatinine-Cystatin C Equations (2012) in the External-Validation Data Set Comprising 1119 Participants.

\begin{tabular}{|c|c|c|c|c|}
\hline \multirow[t]{3}{*}{ Variable } & \multicolumn{4}{|c|}{ Estimated GFR } \\
\hline & Overall & $<60$ & $60-89$ & $\mathbf{9 0}$ \\
\hline & \multicolumn{4}{|c|}{$\mathrm{ml} / \mathrm{min} / 1.73 \mathrm{~m}^{2}$ of body-surface area } \\
\hline \multicolumn{5}{|l|}{ Bias - median difference $(95 \% \mathrm{CI})$} \\
\hline Creatinine equation & $3.7(2.8$ to 4.6$)$ & $1.8(1.1$ to 2.5$)$ & $6.6(3.5$ to 9.2$)$ & $11.1(8.0$ to 12.5$)$ \\
\hline Cystatin $\mathrm{C}$ equation & $3.4(2.3$ to 4.4$)$ & $0.4(-0.5$ to 1.4$)$ & $6.0(4.6$ to 8.5$)$ & $8.5(6.5$ to 11.2$)$ \\
\hline Creatinine-cystatin $\mathrm{C}$ equation & $3.9(3.2$ to 4.5$)$ & $1.3(0.5$ to 1.8$)$ & $6.9(5.0$ to 8.9$)$ & $10.6(9.5$ to 12.7$)$ \\
\hline Average of creatinine and cystatin $\mathrm{C}^{\dagger}$ & $3.5(2.8$ to 4.1$)$ & $0.4(-0.3$ to 0.8$)$ & $6.5(4.6$ to 8.4$)$ & 11.9 (9.9 to 13.9$)$ \\
\hline \multicolumn{5}{|l|}{ Precision - IQR of the difference $(95 \% \mathrm{CI})$} \\
\hline Creatinine equation & $15.4(14.3$ to 16.5$)$ & $10.0(8.9$ to 11.0$)$ & $19.6(17.3$ to 23.2$)$ & $25.0(21.6$ to 28.1$)$ \\
\hline Cystatin $\mathrm{C}$ equation & $16.4(14.8$ to 17.8$)$ & $11.0(10.0$ to 12.4$)$ & $19.6(16.1$ to 23.1$)$ & $22.6(18.8$ to 26.3$)$ \\
\hline Creatinine-cystatin $\mathrm{C}$ equation & $13.4(12.3$ to 14.5$)$ & $8.1(7.3$ to 9.1$)$ & $15.9(13.9$ to 18.1$)$ & $18.8(16.8$ to 22.5$)$ \\
\hline Average of creatinine and cystatin $\mathrm{C}$ equations ${ }^{\dagger}$ & $13.9(12.9$ to 14.7$)$ & $7.9(7.1$ to 9.0$)$ & $15.8(13.9$ to 17.7$)$ & $18.6(16.1$ to 22.2$)$ \\
\hline \multicolumn{5}{|l|}{ Accuracy $-\%(95 \% \mathrm{CI})^{*}$} \\
\hline \multicolumn{5}{|l|}{$1-\mathrm{P}_{30}$} \\
\hline Creatinine equation & $12.8(10.9$ to 14.7$)$ & $16.6(13.6$ to 19.7$)$ & $10.2(6.4$ to 14.2$)$ & $7.8(5.1$ to 11.0$)$ \\
\hline Cystatin $\mathrm{C}$ equation & $14.1(12.2$ to 16.2$)$ & $21.4(18.2$ to 24.9$)$ & $12.7(8.5$ to 17.4$)$ & $2.2(0.6$ to 3.9$)$ \\
\hline Creatinine-cystatin $\mathrm{C}$ equation & $8.5(7.0$ to 10.2$)$ & $13.3(10.7$ to 16.1$)$ & $5.3(2.7$ to 8.2$)$ & 2.3 (0.9 to 4.2$)$ \\
\hline Average of creatinine and cystatin $\mathrm{C}$ equations ${ }^{\dagger}$ & $8.2(6.7$ to 9.9$)$ & $12.1(9.5$ to 14.8$)$ & 6.4 (3.6 to 9.7$)$ & $2.9(1.3$ to 4.9$)$ \\
\hline \multicolumn{5}{|l|}{$1-\mathrm{P}_{20}$} \\
\hline Creatinine equation & $32.9(30.1$ to 35.7$)$ & $37.2(33.1$ to 41.2$)$ & 31.1 (25.1 to 37.4$)$ & $26.5(21.7$ to 31.4$)$ \\
\hline Cystatin $\mathrm{C}$ equation & $33.0(30.3$ to 35.7$)$ & $42.1(38.2$ to 46.1$)$ & 29.3 (23.6 to 35.4$)$ & $19.4(15.4$ to 23.7$)$ \\
\hline Creatinine-cystatin $\mathrm{C}$ equation & $22.8(20.4$ to 25.2$)$ & $28.6(25.1$ to 32.4$)$ & $17.8(13.3$ to 22.9$)$ & $16.2(12.4$ to 20.5$)$ \\
\hline Average of creatinine and cystatin $\mathrm{C}$ equations ${ }^{\dagger}$ & $23.7(21.3$ to 26.1$)$ & $29.1(25.7$ to 32.8$)$ & $17.6(13.2$ to 22.4$)$ & $18.8(14.6$ to 23.2$)$ \\
\hline
\end{tabular}

* The equations are given in Table 2. CI denotes confidence interval, and IQR interquartile range.

${ }^{\dagger}$ Averages are for the estimated GFRs from the CKD-EPI creatinine equation ${ }^{3}$ alone and the CKD-EPI cystatin C equation alone.

*Accuracy was calculated as the percentage of estimates that differed from the measured GFR by more than $30 \%(1-\mathrm{P} 30)$ and the percentage that differed by more than $20 \%\left(1-\mathrm{P}_{20}\right)$.

N Engl J Med. Author manuscript; available in PMC 2015 April 15. 


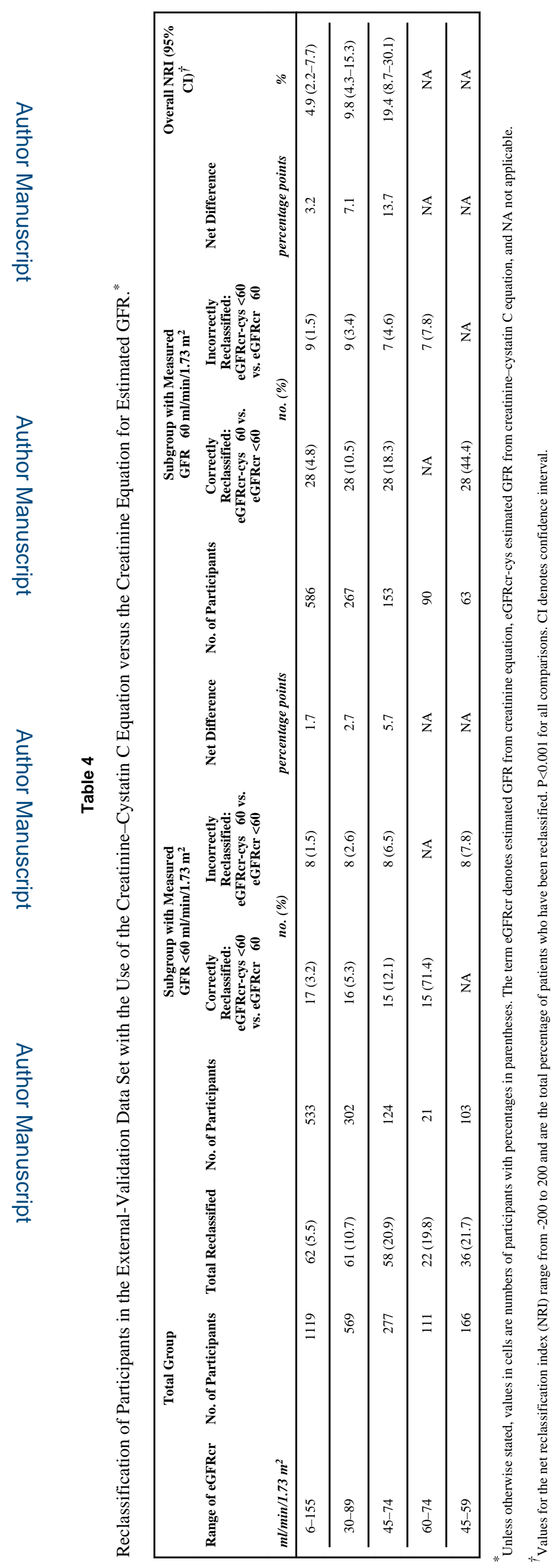

